\title{
COMPARISION OF PHYSICAL FITNESS CHARACTERISTICS OF YOUNG BASKETBALL PLAYERS
}

Authors: Raimundas VENSKAITIS ${ }^{1,2}$ Ligita Aučynienè $^{1,2}$ leva Eglè Jamontaitėét,2 Mykolas Butvila ${ }^{3}$

The Department of Rehabilitation, Physical and Sports Medicine, Faculty of Medicine, Vilnius University ${ }^{1}$, Rehabilitation, Physical and Sports medicine centre, Vilnius University hospital Santaros klinikos ${ }^{2}$, Faculty of Medicine, Vilnius University ${ }^{3}$

Introduction - Basketball is sport, where most of the energy are consumed for high intensity activities: starts, stops, jumps, shots, blocks and rebounds $(1,2,3)$. Intermittent nature of the physical demands requires players to have a high level of fitness (4).

Purpose - To compare physical fitness characteristics of young basketball players.

Method - The research was conducted in the period of June 2017. The research consisted of a sample of 56 basketball players from "Sostinès" basketball school, Vilnius. Evaluation methods used to conduct this research were: questionnaire, McGill test, the Modified Star Excursion Balance Test and standing long jump. Statistical analysis was conducted with "SPSS20" program.

Results - The majority of a group were 14 years old (21 boys, $37,5 \%$ ), 12 years old (14 boys, 25\%), 13 years old (13 boys, $23,2 \%$ ). $62,5 \%$ of the players had 5 workouts during a week in a last season. 38 boys from 56 had a leg trauma during last year. Mcgill test has shown that average flexion result was $183 \pm 119$ (sec), extension $138 \pm 61(\mathrm{sec})$, right-side bridge (RSB) 76 \pm 24 (sec), left-side bridge (LSB) $73 \pm 24$ (sec). Flexion/extension ratio were 1,4 . $\mathrm{RSB} / \mathrm{LSB}$ ratio were 0,92 . $\mathrm{RSB}$ /extension ratio were 0,61. LSB/extension ratio were 0,58. The Modified Star Excursion Balance Test were performed with a shoe and without it. The results with a shoe: right foot $94,57 \pm 8,2$, left foot $94,17 \pm 8,9$. Test results without a shoe were similar and with right foot were $92,87 \pm 8,67$, left foot $92,67 \pm 7,5$. Standing long jump average result of all players were $202,7 \pm 20,1(\mathrm{~cm})$.

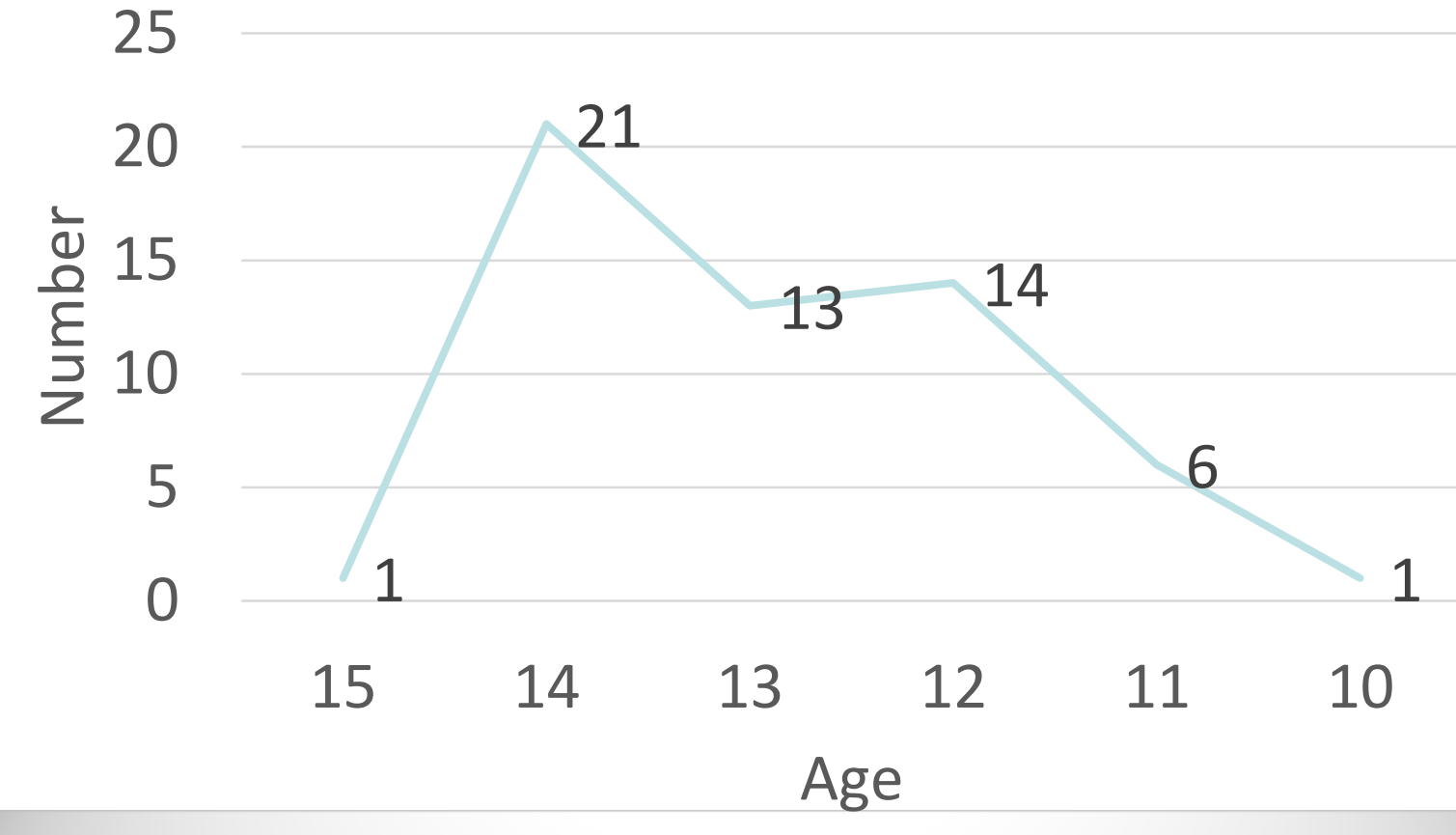

Mcgill test (sec)

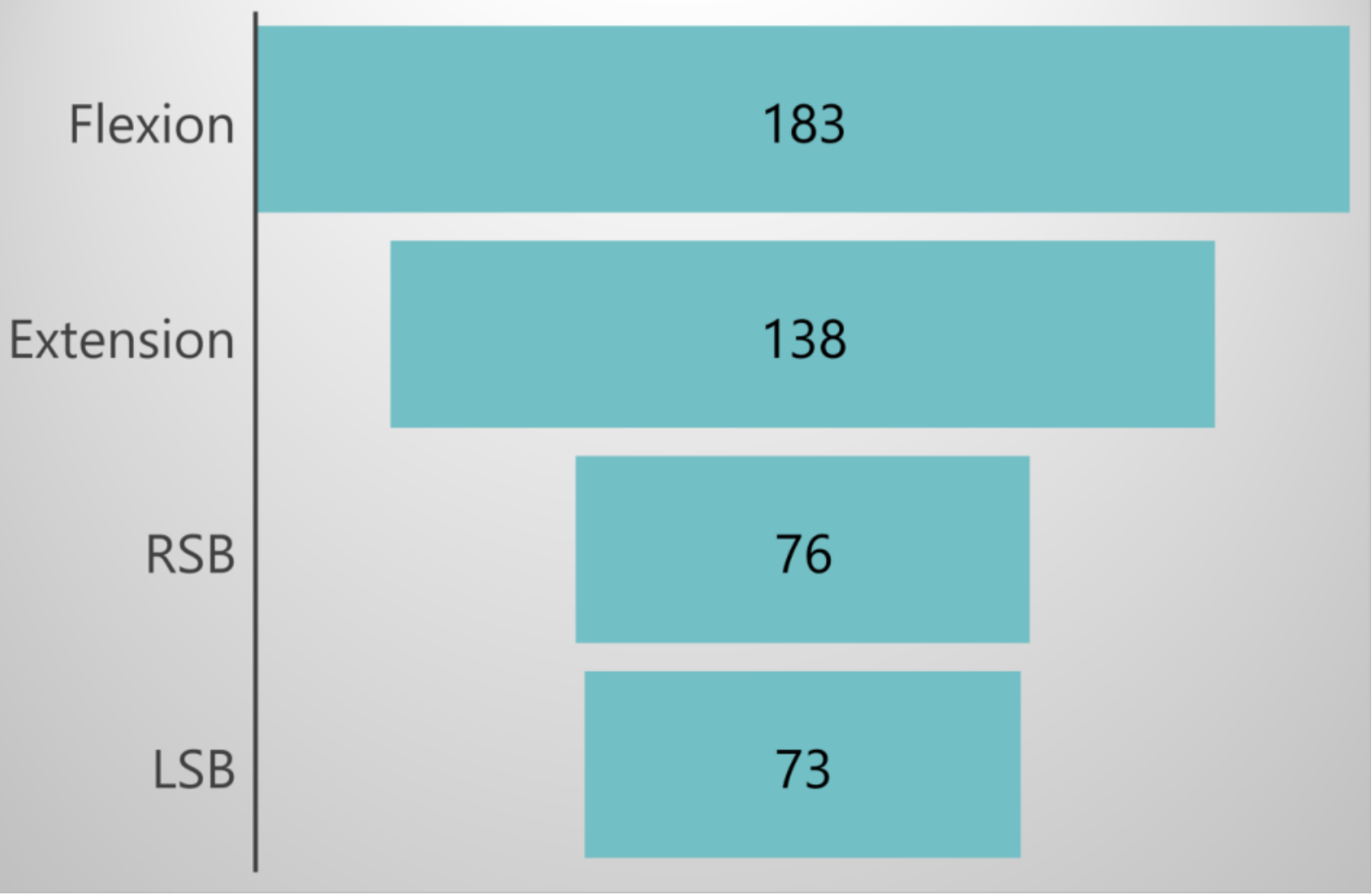

The Modified Star Excursion Balance Test
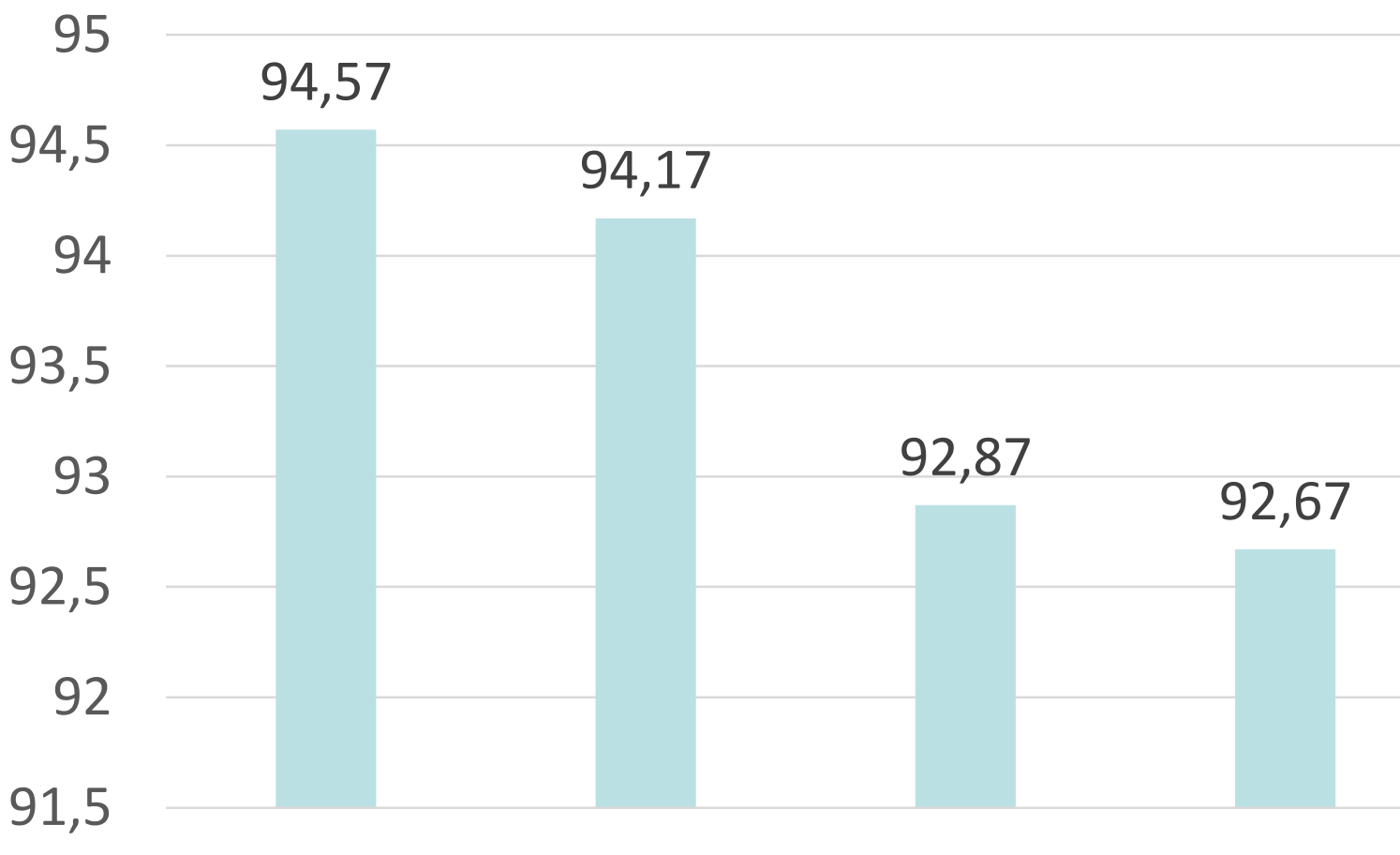

Right foot Left foot Right foot Left foot

Conclusions - The findings of the present study indicates that physical fitness characteristics of young professional basketball players differed from the tests ratios. These findings may elucidate which physical abilities are the weakest and could help trainers to prevent players from trauma and pain. 